DOSSIÊ TEMÁTICO: Ensinar e aprender: metodologias e estratégias

d० https://doi.org/10.22481/praxisedu.v15i35.5657

\title{
DIFERENTES METODOLOGIAS DE ENSINO NA MATEMÁTICA: EXPECTATIVA X EXPERIÊNCIA EFETIVA
}

\author{
DIFFERENT METHODOLOGIES OF TEACHING MATHEMATICS: EXPECTATION X \\ EFFECTIVE EXPERIENCE
}

\begin{abstract}
DIFERENTES METODOLOGÍAS DE ENSEÑANZA EN LA MATEMÁTICA: EXPECTATIVA X EXPERIENCIA EFECTIVA
\end{abstract}

Adriana Guerra

Instituto Federal de Educação, Ciência e Tecnologia Baiano - Brasil

\begin{abstract}
Resumo: Este estudo teve como principal objetivo, analisar as Expectativas e as Experiências Efetivas sobre o processo de ensino e de aprendizagem e as diferentes metodologias de ensino utilizadas nas práticas pedagógicas da área de Matemática, a partir do resultado de uma Pesquisa de Avaliação (Online) respondida por 87 alunos, participantes da pesquisa, do Ensino Médio da Educação de Jovens e Adultos (EJA) da modalidade à Distância da Escola SESI (Serviço Social da Indústria) da cidade de Itapetinga-BA. Um estudo de cunho quali-quantitativo e do tipo intervenção, onde utilizamos para análise os resultados das Pesquisas de Avaliação (Expectativas e Experiências Efetivas), respondidas pelos alunos antes de iniciar e ao finalizar a área de Matemática. Os "medos" demonstrados no resultado inicial da pesquisa foram motivos para o desenvolvimento de práticas de ensino diferenciadas, autônomas e interativas, que não tivessem nenhuma familiaridade com os métodos tradicionais de ensino. Desse modo, os planejamentos foram baseados na Resolução de Problemas, no Raciovitalismo, na Etnomatemática e na Modelagem Matemática, metodologias de ensino, na qual um dos pontos em comum é priorizar o conhecimento prévio do aluno e relacionar com os conteúdos matemáticos escolares. A mediação se concretizou de forma a corresponder à eficácia apresentada pelas tendências, onde despertaram tanto o intelecto quanto as emoções dos alunos. Dado a importância da razão e da emoção caminhar juntas numa didática, porque estabelece fortes vínculos no processo de ensino e de aprendizagem. Enfim, obtivemos excelentes resultados referente a superação de medos e da aprendizagem matemática dos alunos, nas quais foram evidentes nos resultados demonstrados na Pesquisa de Avaliação.
\end{abstract}

Palavras-Chave: Metodologias de ensino. Práticas de ensino. Pesquisa de Avaliação.

\begin{abstract}
This study had as main goal to analyze the Expectations and Effective Experiences about the teaching and learning process and the different teaching methodologies used in the pedagogical practices of the Mathematics area, based on the results of an Online Assessment, answered by 87 students, participants of the research, of the High School of Young and Adult Education (EJA) of the distance modality of the SESI School (Social Service of Industry) in Itapetinga-BA. A quantitative and intervention-type study, where we used the results of the Evaluation Surveys (Expectations and Effective Experiences), which were answered by the students before starting and finishing the
\end{abstract}


Mathematics area. The "fears" demonstrated in the initial research result were reasons for the development of differentiated, autonomous and interactive teaching practices that had no familiarity with traditional teaching methods. Therefore, the planning was based on Problem Solving, Raciovitalism, Ethnomathematics and Mathematical Modeling, teaching methodologies, in which one of the common points is to prioritize the student's previous knowledge and relate to the mathematical contents of the school. The mediation took place in a way that corresponded to the efficacy presented by the tendencies, in which both the intellect and the emotions of the students were awakened. Given the importance of reason and emotion to walk together in a didactic, because it establishes strong bonds in the process of teaching and learning. Finally, we obtained excellent results regarding the overcoming of fears and the mathematical learning of the students, in which they were evident in the results demonstrated in the Evaluation Survey.

Keywords: Evaluation Research. Teaching methodologies. Teaching practices.

Resumen: Este estudio tuvo como principal objetivo analizar las Expectativas y las Experiencias Efectivas sobre los procesos de enseñanzas y aprendizaje y las diferentes metodologías de enseñanza desarrolladas en las prácticas pedagógicas dentro del espacio de Matemática, a partir de la salida del resultado de una Investigación de Avaluación (Online) respondida por 87 alumnos, participantes del estudio, en la educación Bachillerata de Jóvenes y Adultos (EJA) en la modalidad a Distancia de la Escuela SESI (Servicio Social de la Industria) de la ciudad de Itapetinga-BA. Un estudio de naturaleza cuali-cuantitativo y de modo intervencionista, donde se utilizó para los análisis los resultados de las Investigaciones de Avaluación (Expectativas y Experiencias Efectivas), respondidas por los alumnos antes de iniciar y al finalizar las clases de Matemática. Los "miedos" demostrados en el resultado inicial del estudio fueron motivos para el desarrollo de las prácticas de enseñanza diferenciadas, autónomas e interactivas, que no tuviesen ninguna relación con los métodos tradicionales de enseñanzas. De ese modo, las planeaciones fueron fundamentadas en la Resolución de Problemas, en el Raciovitalismo, en la Etnomatemática y en los moldes Matemáticos, metodologías de enseñanzas, en la cual uno de los puntos habituales es priorizar el conocimiento anticipado del alumno y relacionar con los contenidos matemáticos escolares. La mediación se concretizó de forma correspondiente a la eficacia presentada por las afinidades, donde despertaron tanto el intelecto cuanto las emociones de los alumnos. Dado a la importancia de la razón y de la emoción caminar juntas en una didáctica, porque establece fuertes vínculos en el proceso de enseñanza y aprendizaje. Al final, obtuvimos excelentes resultados referente a la superación de miedos y de aprendizaje matemática de los alumnos, en las cuales fueron evidentes en los resultados demostrados en la Investigación de Avaluación.

Palabras-Clave: Investigación de Avaluación. Metodologías de enseñanza. Prácticas de enseñanza.

\section{Introdução}

Qualquer disciplina é chata, mas a tal das Exatas (Física, Química e Matemática)! Vamos dizer mais especificamente a Matemática, pois essa começa a ser estudada desde os anos iniciais (na educação infantil também ela se faz presente). Mas, será o porquê de tantos alunos serem revoltados ou mesmo odiar o tal dos cálculos? Esse é um questionamento que durante a minha experiência na docência (Ensino Fundamental e Médio tanto no Ensino Regular quanto na Educação de Jovens e Adultos (EJA); Curso Pré-Vestibular e Técnico) sempre busquei respostas. E acredito que estou chegando nesse alvo. 
Enfim, todas as disciplinas de Ensino possuem as suas particularidades e com isso existem alunos que gostam ou que não gostam de determinada disciplina. No entanto, pela minha experiência e pelas pesquisas realizadas, sempre, com novas turmas que vou lecionar, é notório o quanto a Matemática é a vilã, aquela que grande parte da turma não suporta ou tem medo. Com isso, comecei a pensar em algo diferente, que promovesse certo contentamento para o aluno estar naquele espaço de ensino e de aprendizagem participando das aulas de Matemática.

Confesso, que no início da minha carreira docente não via a hora de sair da sala de aula e que os meus alunos desejavam, muito mais, a mesma coisa, visto que todas as práticas de ensino eram baseadas no tradicionalismo e, ainda, eu era muito insociável com os mesmos. Mas, que bom que existem as experiências e o poder da reflexão, pois com o tempo percebi que era necessário mudar o meu comportamento e a minha prática. No entanto, entendi essa necessidade, somente, quando me descobri professora, pois esse é um dos pontos relevantes primeiro, gostar do que estamos fazendo. E, somente, após esta descoberta, comecei a ter curiosidade, a buscar e a estudar diferentes práticas pedagógicas, a fim de melhorias a minha função de professora.

A cada prática de ensino, a cada ano que passava, a cada convivência com os colegas de profissão, a cada resultado dos meus alunos, eu percebia a indispensabilidade de mudar. Com isso, comecei a ler, a pesquisar, a buscar coisas novas para a minha prática de ensino e assumir de verdade quem eu sou, pois eu não era uma pessoa insociável, mas queria mostrar para os meus alunos que eu era "autoridade" e, somente, após algum tempo percebi que isso era um pensamento hipócrita, pois nada disso é ou seria necessário.

Enfim, houve muitas mudanças nesse percurso, após perceber que seria fundamental está mais próxima dos meus alunos, além de assumir e desenvolver novas metodologias de ensino para que os meus alunos pudessem sentir a alegria de está naquele espaço de aprendizagem, de alguma forma, se divertindo e aprendendo.

Com isso, este estudo buscou analisar as Expectativas (Antes) e as Experiências Efetivas (Depois), sobre o processo de ensino e de aprendizagem e as diferentes metodologias de ensino utilizadas nas práticas de ensino da área de Matemática, a partir do resultado de uma Pesquisa de Avaliação (Online) respondida pelos alunos do Ensino Médio da Educação de Jovens e Adultos (EJA) da modalidade à Distância da Escola SESI (Serviço Social da Indústria) da cidade de Itapetinga-BA.

Nesta pesquisa houve a participação de 87 alunos, onde os mesmos responderam anonimamente um questionário online (Pesquisa de Avaliação), antes mesmo de iniciar a área 
de Matemática, a fim de a tutora/professora ter conhecimento sobre as suas "Expectativas", referente a Matemática e após o fim dos estudos desta área, os mesmos responderam outros questionamentos correspondentes as suas "Experiências Efetivas" durante o processo de ensino e de aprendizagem.

Desse modo, os resultados foram bastante eficazes, pois contribuíram como instrumento para conhecer a realidade dos alunos, quanto ao ensino, a aprendizagem, os seus medos e anseios e, ainda, serviram de orientação para os futuros planejamentos que poderiam está sendo desenvolvidos.

\section{A Melhor Aula para o Meu Aluno}

Já se perguntou em sua prática: qual a melhor aula para o seu aluno? Colocando-se como aluna ou aluno: qual seria a melhor aula para você? Se analisar em sua prática, independente da disciplina a qual leciona, perceberá a felicidade de um aluno quando ele está aprendendo naquela determinada aula. E, com certeza, por consequência dessa aprendizagem ele comentará para alguém que aquela foi a melhor aula, até ocorrer outra que lhe possibilitará mais conhecimentos e mais curiosidades.

Para isto, um dos critérios é o aluno, também, assumir o papel de importância na sala de aula e não apenas o professor, ou seja, o aluno deve ser protagonista, participante ativo, construtor do seu próprio conhecimento, e para que isso aconteça é necessário possibilitar a sua autoconfiança e a sua autonomia em sala de aula. Nesta ocasião, o professor deve fazer o aluno se sentir livre para expor as suas ideias, criar oportunidades para a sua participação, relacionar os conteúdos estudados no momento com situações do cotidiano. Essa é uma prática de ensino capaz de promover conhecimento e satisfação, além de o aluno perceber a necessidade e a aplicabilidade a sua vida, o que pode não permitir tal esquecimento.

Todavia, para isso é essencial certo planejamento, pois se espera que em todo processo de ensino haja aprendizagem, porém deve-se fugir de improvisos. Essa é uma responsabilidade do docente, quando ele se sente comprometido e preocupado com a aprendizagem dos seus alunos. O ensino conduzido por improvisações, certamente, pontos importantes deixarão de ser desenvolvidos, mas com o delineamento de cada etapa, poderá possibilitar certa orientação para o professor desenvolver melhor o processo de ensino e de aprendizagem, apesar das possíveis surpresas que podem acontecer no seu desenvolvimento. Moretto (2014), quando declara: 
A questão por que planejar parece ter resposta óbvia: planeja-se porque "não há ventos favoráveis para quem não sabe para onde navega". Na prática, no entanto, a questão do planejamento no contexto escolar não parece ter a importância que deveria ter. Há quem pense que tudo já está planejado nos livros-texto ou nos materiais adotados como apoio ao professor. Há, ainda, quem pense que sua experiência como professor seja suficiente para ministrar aulas com eficiência. No entanto, acreditamos que qualquer atividade da nossa vida exige, de uma forma ou de outra, um planejamento. (MORETTO, 2014, p.100).

É necessário ter conhecimento: dos recursos didáticos a serem utilizados; o "porquê" abordar tal conteúdo; das possibilidades do aluno compreender ou não os questionamentos, as explanações realizadas durante a aula; e, ainda, em qual momento o seu aluno será ou poderá ser avaliado. Seguir os capítulos do livro-texto da escola, considerando como o seu planejamento, isto conduzirá facilmente a uma aula, onde poderá não ser presenciado o interesse do aluno pela aprendizagem, pois neste momento ele apenas ouve e escreve, o que deixa muito monótono e entediante.

Outro fator negativo é o professor considerar, que o seu tempo na docência define o quanto bom ele é na sua função. Desse modo, os mesmos métodos de ensino que são desenvolvidos anualmente com as suas turmas, desenvolvem os mesmos com aquelas diferentes turmas que chegam à escola nos anos seguintes. Um ensino baseado no tradicionalismo, onde nesse espaço de ensino e de aprendizagem, este professor assume o papel principal, ele que é o detentor do saber e transmissor do conhecimento.

Esses métodos de ensino utilizados, com certeza, não será uma novidade e nem despertarão interesse e nem curiosidade alguma ao aluno, pois o aluno do mundo contemporâneo é ativo, quer participar das aulas, quer falar das tecnologias, das redes sociais, do seu cotidiano e entre outras coisas, e claro que é possível trazer essas realidades para serem abordadas em sala de aula. Se isso que os chama atenção, é essencial discutir, relacionar os conteúdos para aquilo que está próximo à vivência do aluno. Em função disso, poderá promover uma aprendizagem interativa, prazerosa e interessante para o seu público, pois o mesmo poderá apropriar-se de todo o conhecimento com mais aplicabilidade e propriedade.

Entretanto, vale destacar que o planejamento é a rota de saída, mas sem a certeza dos pontos de chegada. Sendo assim, todo planejamento tem como objetivo de determinar a correspondência entre a previsibilidade e a surpresa, mesmo com o uso de diversas metodologias de ensino. Em outras palavras, no planejamento deve-se considerar que em qualquer relação, possivelmente, encontrará componentes da incerteza, da singularidade e do conflito de valores (MORETTO, 2014). Em síntese, um planejamento haverá, sempre, 
determinado objetivo, porém isso não implica que o mesmo será totalmente alcançado, mas não implica afirmar que esta não é uma tarefa importante no processo de ensino e de aprendizagem.

Em suma, é evidente o quanto é fundamental uma prática de ensino inovadora, interativa, a fim de que os alunos tenham prazer de está naquele espaço de aprendizagem. $\mathrm{O}$ professor desta atualidade deve ser inovador, humorista, criativo e empreendedor na sala de aula, nos seus planejamentos e no seu desenvolvimento, em outras palavras, deve ser convincente ao seu aluno. Enfim, uma aula boa para qualquer aluno é aquela na qual ele aprende, logo o professor precisa ser um artista para inventar e reinventar com o objetivo de arrancar aplausos da sua plateia no final da sua atuação.

\section{As Diferentes Metodologias desenvolvidas no Ensino de Matemática}

Há um grande desafio para aqueles jovens e adultos, que por algum motivo desistiram da escola, ou melhor, se afastaram das salas de aula e retardaram o período da conclusão dos seus estudos, pois muitos deles se sentem envergonhados pela atual idade, se sentem "velhos" para assumir o papel de estudante, novamente, ou mesmo pelo medo de não consegui aprender, devido o tempo que ficaram sem estudar.

Consequentemente, não deixa de ser, também, um desafio para a escola e, ainda, maior para o professor, porque existirá certa cobrança e este deve ser capaz de criar um ambiente agradável para aprendizagem do seu aluno na sala de aula, promover práticas de ensino diferenciadas, distantes dos métodos tradicionais, onde o aluno seja autônomo, ativo, protagonista, participante e construtor do seu próprio conhecimento, pois nessa contemporaneidade as inovações são necessárias. Para isso, é essencial o professor possuir certo conhecimento sobre as diferentes metodologias de ensino existentes, mais especificamente de Matemática, que podem possibilitar práticas de ensino dinâmica, interativa e divertida, que gerem determinado contentamento e aprendizagem.

Dentre as metodologias de ensino de Matemática, são evidentes neste estudo: o Raciovitalismo, a Resolução de Problemas, a Etnomatemática e a Modelagem Matemática. Todas essas metodologias de ensino priorizam o conhecimento matemático aprendido fora da escola, como um dos principais instrumentos para mobilizar o processo de ensino e de aprendizagem. 
Uma vez que, a Matemática, não somente a nível nacional, mas internacionalmente, também, é desenvolvida sem vínculos com os problemas que fazem sentido na vida dos estudantes. Os aspectos mais interessantes desta área, como resolver problemas, discutir ideias, conferir informações e ser provocado, dificilmente são explorados na escola. $\mathrm{O}$ ensino se resume a regras mecânicas que ninguém sabe, nem mesmo o professor, para que servem. (SADOVSKY, 2007, s/p).

Entretanto, o Raciovitalismo, conforme D’Ávila e Ferreira (2018), é uma nova concepção pedagógica e nessa concepção tanto o professor quanto os alunos assumem o perfil de mediadores numa perspectiva compartilhada e autônoma. Ao professor apresentar determinado conteúdo, ele parte de situações vividas pelos alunos, o que o possibilita o compartilhamento de impressões, de hipóteses deduzidas pela turma, onde se relaciona essas metáforas ao conhecimento que se pretende trabalhar. A relação estabelecida entre o aluno e o professor não se esgota nela mesma, pois ela muda de perspectiva, se estende e passa a ser configurada num elo: todos e todos. Nessa concepção os alunos, também, são mediadores de conhecimento, autores com direito a imaginação, a expressão e ao desenvolvimento de um pensamento autônomo (D’ÀVILA; FERREIRA, 2018).

Para Onuchic (1999), ensinar a Matemática a partir da Resolução de Problemas, as situações problemas são fundamentais não apenas como um propósito de se aprender esta área de conhecimento, mas como primeiro passo para se fazer isso. Um dos objetivos de se aprender matemática é o de poder transformar determinados problemas não habituais em habituais. Deste modo, a aprendizagem pode ser vista com um movimento do concreto (um problema do mundo real que serve como exemplo do conceito ou da técnica operatória) para o abstrato (uma representação alusiva de um grupo de problemas e técnicas para operar com esses símbolos) (ONUCHIC, 1999). O problema é visto como um componente que pode possibilitar e estabelecer um processo de aquisição de conhecimento. Nesta perspectiva, situações problemas são propostas ou formuladas de forma a favorecer a construção prévia de conceitos para a apresentação correta da linguagem matemática (ANDRADE, 1998).

O ensino de matemática não pode ser vedado e muito menos elitista, visto que é necessário considerar a realidade sociocultural do aluno, o ambiente que vive e os seus conhecimentos prévios (D’AMBRÓSIO, 2002). A Etnomatemática apresenta uma matemática efetiva não abordada na escola, mas sim no ambiente familiar ou na sua comunidade. A principal proposta pedagógica da Etnomatemática é implementar a matemática como um elemento vivo, de modo a encarar situações reais no tempo (agora) e no espaço (aqui). E isto deve, consequentemente, está relacionado as raízes culturais neste espaço/tempo, assim como da sua dinâmica cultural (D’AMBRÓSIO, 2002). 
A Modelagem Matemática procura revelar a importância dessa área referente ao conhecimento e a compreensão da realidade vivida, além de valorizar o pensamento crítico e reflexivo do aluno (BASSANEZI, 2002). Essa tendência modifica problemas da realidade em problemas matemáticos, o que possibilita resolver de modo a interpretar suas soluções na linguagem do mundo real (BASSANEZI, 2002). De acordo a Bassanezi (2002), a aprendizagem desenvolvida através desta metodologia de ensino, simplifica a combinação dos aspectos lúdicos da matemática com a sua capacidade de aplicações. E com este tipo de material o aluno compreende alternativas no direcionamento das suas competências ou formação acadêmica.

Vale ressaltar que não é mais suficiente o aluno aprender Matemática e saber utilizá-la para resolver problemas cotidianos, pois além desses saberes é imprescindível que o aluno seja apto de interpretar e agir numa situação social e política estruturada pela Matemática (ALMEIDA e DIAS, 2004). E essas habilidades, estas tendências são capazes de proporcionar aos alunos, visto que através dessas metodologias de ensino:

[...] o papel do professor muda do papel de comunicador de conhecimento para o de observador, organizador, consultor, mediador, interventor, controlador, e incentivador da aprendizagem. O professor lança questões desafiadoras e ajuda os alunos a se apoiarem, uns nos outros, para atravessar as dificuldades. O professor faz a intermediação, leva os alunos a pensar, espera que eles pensem, dá tempo para isso, acompanha as suas explorações e resolve, quando necessário, problemas secundários. (ONUCHIC, 1999, p. 216).

Enfim, são várias as metodologias de ensino que o professor pode inserir na sua prática de ensino, no entanto é fundamental saber como trabalhar cada uma delas, pois não são de simples abordagens, exige-se conhecimento e flexibilidade para desenvolvê-las. Dentre elas, são notórios alguns pontos comuns como a matemática aprendida fora da escola, considerada como prioridade no processo de ensino e de aprendizagem. Nessas abordagens, a curiosidade do aluno em aprender deve ser instigada. Conforme Bassanezi (2002), não se pode cogitar a matemática como importante, simplesmente, por determinada definição aleatória ou eventualmente porque poderá realizar uma aplicação, pois a sua importância deve consistir no fato de poder ser tão agradável quanto interessante.

\section{Procedimento Metodológico}

Esta pesquisa foi realizada com 87 alunos do Ensino Médio $\left(1^{\circ}, 2^{\circ}\right.$ e $3^{\circ}$ ano $)$ da Modalidade à Distância da Escola SESI na cidade de Itapetinga-BA. Os encontros/aulas, na 
qual denominamos como Oficinas são desenvolvidas semanalmente (uma vez na semana), onde os alunos estudam uma única área1 por vez, durante 40 a 50 dias. A análise foi realizada na área de Matemática e suas Tecnologias, que teve início no dia 12 de novembro de 2018 e finalizou em 21 de dezembro deste mesmo ano, totalizando quatro oficinas com estes alunos.

Com isso, buscamos analisar as Expectativas (Antes) e as Experiências Efetivas (Depois), sobre o processo de ensino e de aprendizagem e as diferentes metodologias de ensino utilizadas nas práticas de ensino da área de Matemática, a partir do resultado de uma Pesquisa de Avaliação (Online) respondida pelos alunos do Ensino Médio da Educação de Jovens e Adultos (EJA) da modalidade à Distância da Escola SESI (Serviço Social da Indústria) da cidade de Itapetinga-BA.

De abordagem tanto qualitativa quanto quantitativa (quali-quantitativa ou quantiqualitativa), que eventualmente podem ser distintas, porém de alguma forma se correlacionam e favorece o levantamento e análise de dados qualitativos e quantitativos, simultaneamente. Segundo Gil (1999) um estudo com esta característica, possibilita a obtenção de uma análise mais aprofundada sobre o objetivo e, ainda, sobre a problemática.

Considerada do tipo intervenção, onde houve a (GIL, 1999) mediação (mudanças, inovações) desenvolvida propositadamente pelo professor/pesquisador sobre as suas práticas pedagógicas, porém devem ser preparadas e desempenhadas a partir de determinado referencial teórico, com o objetivo de possibilitar melhorias no processo de ensino e de aprendizagem. Nessa conformidade, testificar a veracidade da referida fundamentação teórica e contribuir na construção de conhecimento dos alunos.

Para a coleta de dados utilizamos os resultados apontados na Pesquisa de Avaliação, disponível online para os alunos responderem antes (Perspectiva) de iniciar as Oficinas de Matemática, com os devidos questionamentos: Qual é o seu sentimento com a Área de Matemática? O que você espera da Área de Matemática? Existe algum medo relacionado a Área de Matemática? Caso tenha respondido Sim, quais são os seus medos relacionados a essa área de conhecimento?

Ao finalizar os estudos da área os alunos voltaram a ter acesso a Pesquisa de Avaliação (Experiência Efetiva), mas agora com outras perguntas: Como foi a sua experiência na Área de Matemática? Existia medo com a Área de Matemática? Se Sim, como ficou após

\footnotetext{
${ }^{1}$ Na Escola Sesi são desenvolvidas quatro áreas de conhecimento: Linguagem e suas Tecnologias, Ciências Humanas e suas Tecnologias, Ciências da Natureza e suas Tecnologias e Matemática e suas Tecnologias.
} 
esse período de Ensino? O que diria sobre o ensino com a tutora/professora da área de Matemática?

O questionário foi construído com várias alternativas (múltiplas respostas), no qual os participantes tiveram a liberdade de marcar mais de uma delas. $\mathrm{O}$ que de modo percentual, poderá representar um número maior do que o $100 \%$, o que seria a totalidade, quando comparado ou somado com as demais opções escolhidas.

O maior objetivo da Pesquisa de Avaliação é verificar o nível de expectativas, experiências e de euforia dos alunos, a partir da interação no processo de ensino e de aprendizagem, com os próprios colegas e com o professor. Os seus resultados obtidos podem favorecer instrumentos significativos na prática de ensino do professor, pois possibilita um importante feedback para a reflexão e análise sobre o seu exercício, de modo a tencionar a melhoria contínua do processo de ensino e aprendizagem (UFRB, 2015).

As Oficinas se configuraram como um grande elemento, também, para análise desta pesquisa, através da escrita dos Relatos de Experiência dos alunos, onde os mesmos apontaram, individualmente, no fim de cada Oficina o que e como foi cada uma. Comparando todas as ocorrências (as participações, os questionamentos, os comportamentos, as dúvidas e as avaliações analíticas que foram realizadas em todo o momento dos e com os alunos) com os resultados da Pesquisa de Avaliação, percebemos a sua veracidade.

Para a estruturação da escrita utilizamos a Análise de Conteúdo, a fim de buscar compreender aquilo que está subtendido nas falas ou mesmo nas escritas, das quais o pesquisador se dedica a responder, uma procura de outras realidades por meio de mensagens (BARDIN, 2010).

Desse modo, categorizamos em dois Eixos: Eixo 1 - Expectativas (subdividido em 2 Subeixos), onde o primeiro Subeixo, teve por objetivo conhecer os anseios dos alunos sobre o processo de ensino e de aprendizagem da área de Matemática, e o segundo Subeixo, caracterizar os seus medos referentes a Matemática.

O Eixo 2 - Experiências Efetivas (subdividido em 3 Subeixos). O primeiro Subeixo buscou analisar como foram as experiências vivenciadas pelos alunos durante o processo de ensino e de aprendizagem na área de Matemática. O segundo, verificar como ficaram os seus medos após todo o processo de ensino e de aprendizagem. E o último Subeixo, avaliar a prática de ensino da tutora/professora da área de Matemática.

Por fim, houve a construção de um rol de escritas, através das análises realizadas no intuito de alcançar o objetivo dessa pesquisa. O que foi analisado quali-quantitativamente, por 
meio das inferências dos números apresentados na Pesquisa de Avaliação e dos Relatos de Experiência, respondidos por todos os alunos que participaram de todas as Oficinas.

\section{Análise e Resultados da Pesquisa de Avaliação}

No primeiro encontro foram evidentes muitas situações demonstradas no resultado da Pesquisa de Avaliação (Eixo 1 - Expectativas), a qual os alunos responderam antes de iniciar a área de Matemática.

O Subeixo 1, relacionado aos anseios dos alunos sobre o processo de ensino e de aprendizagem da área de Matemática, o resultado causou um pouco de surpresa, mas não ruim. Visto que em qualquer lugar onde quer que chegue, quando se fala de Matemática, é notório o temor das pessoas, referente ao cálculo. E nessa análise, do total de 87 alunos participantes na pesquisa: 42 afirmaram Gostar de Matemática e 15 Não Gostam, grande número admitiu a sua simpatia com a área. Entretanto, 37 assumiram Ter Medo e 22 Não Ter Medo. Veja o gráfico, abaixo:

Gráfico 1 - Expectativa: Qual é o seu sentimento com a Área de Matemática?

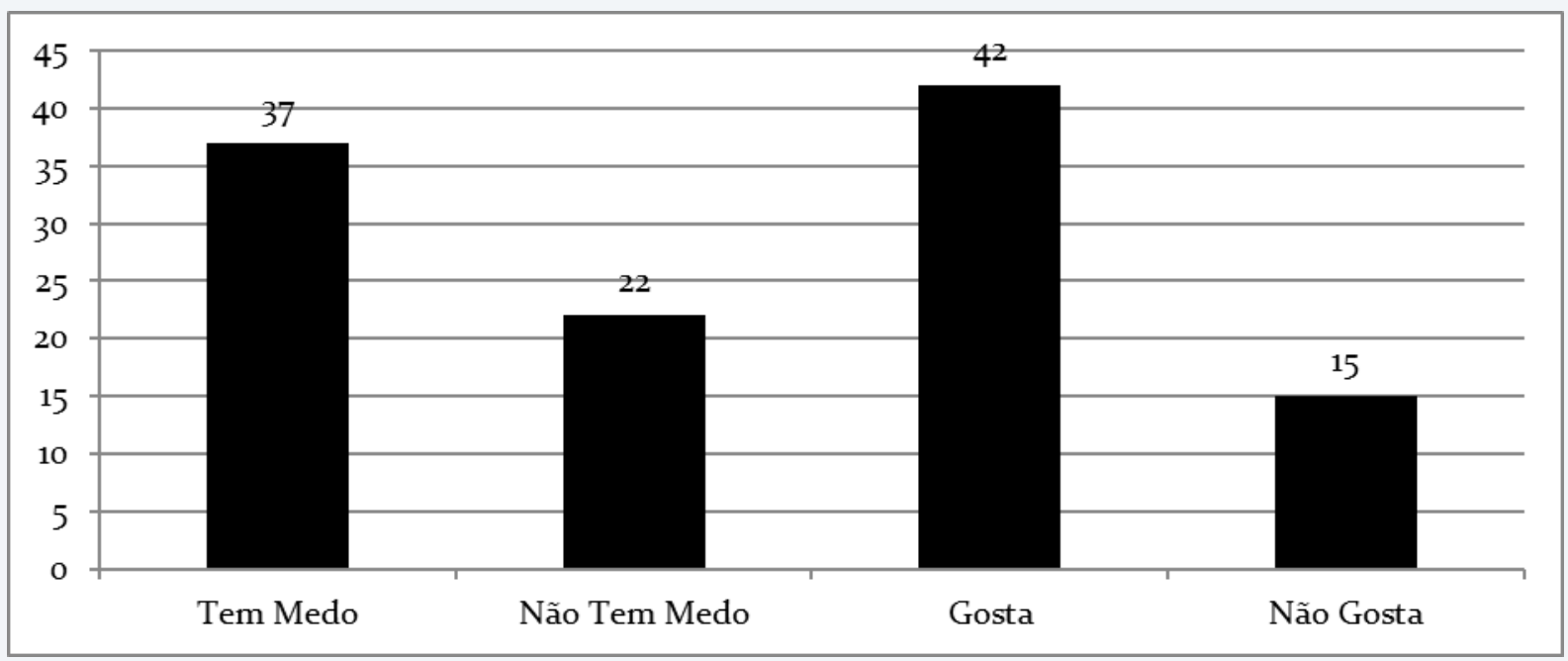

É um número surpreendente, quando fica evidente que dentre o total, quase 50\% (42) afirmaram Gostar de Matemática, onde aqueles que Não Gostam (15) foram bem menor. Claro, que em meio a totalidade muitos omitiram, não quisera responder, talvez por ter dúvida ou mesmo coragem de reconhecer se Gostam ou Não Gostam da temida área. Nessa análise, podemos perceber, ainda, a quantidade de alunos que Tem Medo (37) de Matemática, o que muito provável pode existir algum aluno, dentre estes que mesmo gostando, possuem algum 
temor, assim como os outros que apontaram Não Ter Medo (22), pode Gostar ou Não Gostar de Matemática.

A primeira Oficina foi um momento crucial para esta análise, pois o cansaço diário, as preocupações, as ansiedades, os receios ou as euforias estavam estampados em cada rosto. $\mathrm{O}$ interesse ou desinteresse, o querer ou não querer de estar naquele espaço de aprendizagem, talvez fosse motivador ou desmotivador para qualquer professor ou professora. Que horas começa? Que horas termina? Como será a Prova? Está fácil aqui, mas na prova! Enfim, um momento desafiador, onde o planejamento pode, ainda, ser um problema - alcançar ou não alcançar os objetivos traçados. Consideravelmente, muito difícil que a aprendizagem ou o contentamento atinja a todos, mas atingir a grande parte do público, já valerá por todo o esforço, organização e estudos dedicados à elaboração de todo o plano de aula.

Ao questioná-los sobre o que esperava da área de Matemática, os alunos responderam diferentes situações: ser aprovado (52), ter bom desempenho (48), superar as dificuldades (43), ser momento de muita aprendizagem (30), aprender para usufruir profissionalmente (28), ter melhor compreensão (27), adquirir novas experiências (27), melhorar as habilidades (26), vencer o medo (24), ser um ensino divertido (24), vencer esta etapa (24), surpreender a si mesmo (19), seja fácil (18), ensino produtivo (15), mais paciência para aprender (14), seja um ensino diferenciado (10) e gostar de Matemática (07).

Gráfico 2 - Expectativa: O que você espera da Área de Matemática?

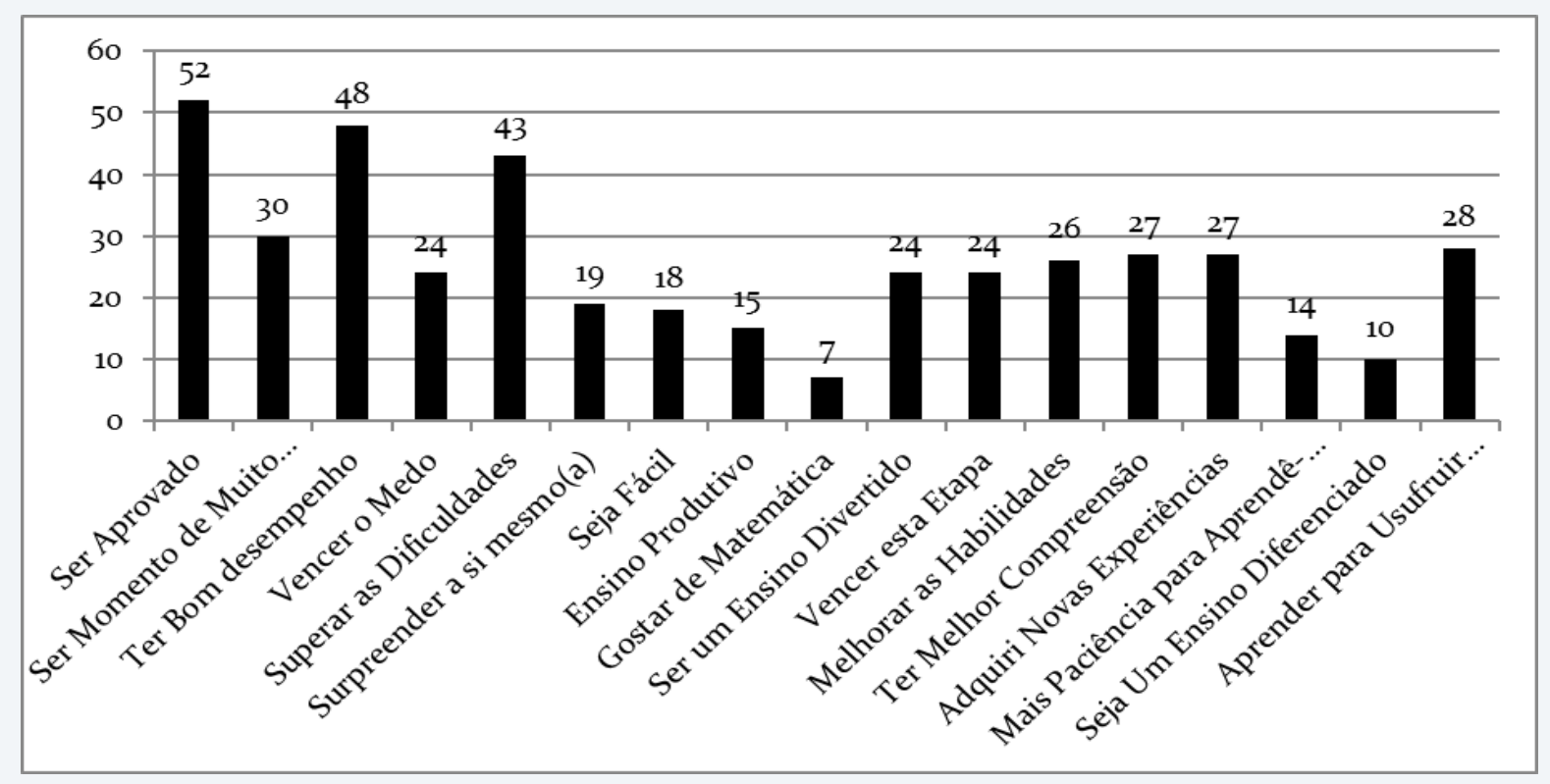

Com isso, percebemos que uma das maiores preocupações desses alunos é com a Aprovação (52), o que está associada ao Bom Desempenho (48), que para isso é um dos pontos cruciais. Visto que é normal em uma turma encontrar muitos alunos que tem medo, e 
essa situação é uma condição que pode impedir de o aluno aprender, por conta disso muitos apontaram a necessidade de vencer o medo (24), superar as dificuldades (43), melhorar as habilidades (26), gostar de Matemática (07), pois este é um ponto que pode comprometer na aprendizagem, pois quando não gostamos, eventualmente, não nos esforçamos em estudar ou para estar naquele ambiente.

Consequentemente, isso vai exigir tanto do professor para promover um ensino de muito aprendizado (30); divertido (24); produtivo (15); diferenciado (10), o que requer ser distante dos métodos tradicionais de ensino; mais simples e fácil de compreensão (18), quanto do próprio aluno em ter mais paciência para aprender (14), a fim de ter melhor compreensão (27) e surpreender a si mesmo (19) e com isso adquirir novas experiências (27) e vencer essa etapa (24) com êxito, de modo que esses conhecimentos não fiquem apenas na sala de aula, mas que leve para a sua vida, para usufruir tanto na vida pessoal quanto profissionalmente (28).

No Subeixo 2, caracterizamos os medos dos participantes referente a Matemática. Nesse momento, os mesmos foram questionados, novamente, se existe medo ou não em Matemática: tem medo (69) e não tem medo (18). Aqueles que responderam sim assumiram como medo: por ter muito tempo sem estudar (40), de não aprender (34), da reprovação (26), por ser difícil (26), das fórmulas (20), de porcentagem (16), de tudo da Matemática (15), de Geometria (15), dos gráficos (14), do momento da prova (13), do raciocínio lógico (11), das situações problemas (10), dos números (06).

Gráfico 3 - Expectativa: Quais são os seus medos relacionados a essa área de conhecimento?

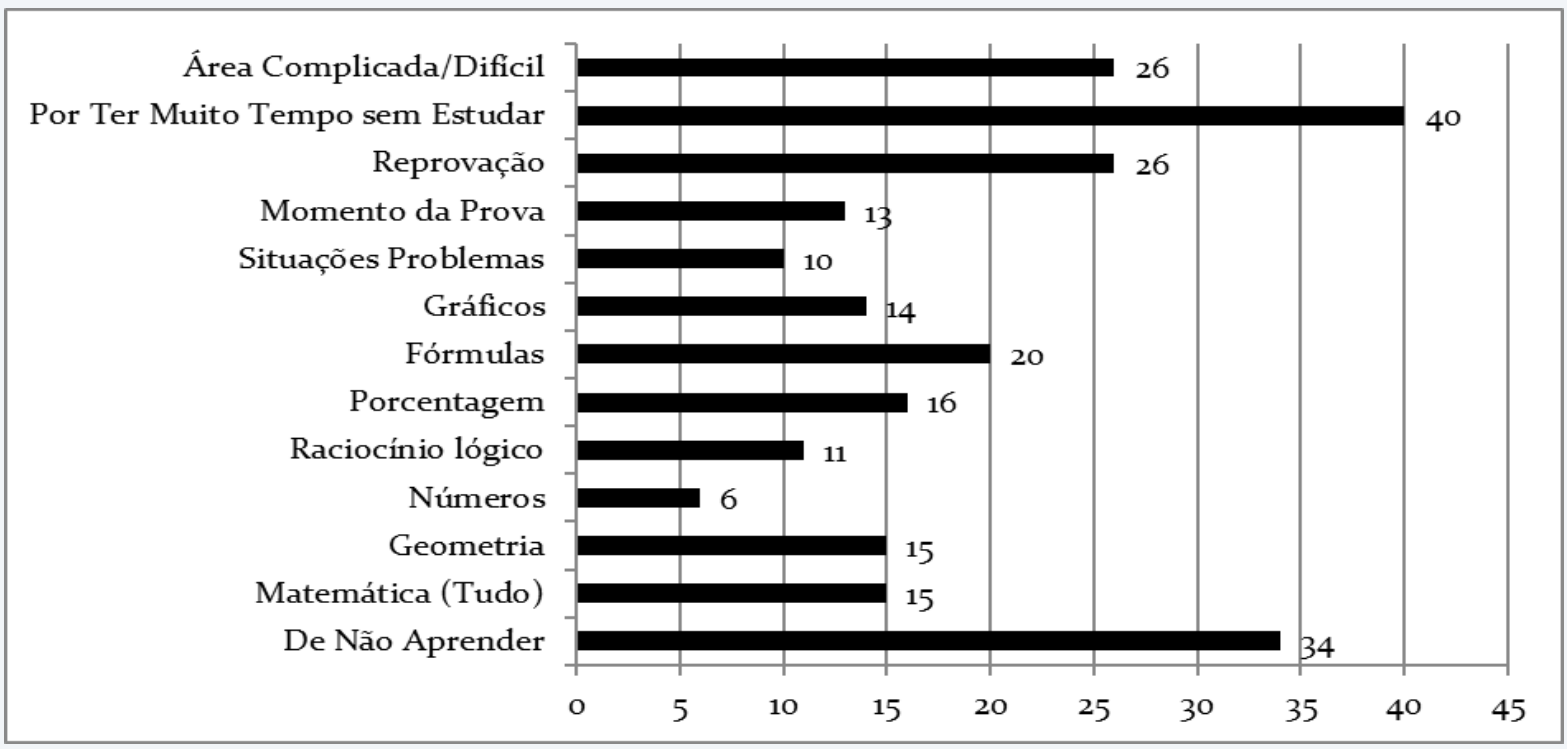


Nesse contexto, os alunos temem em não aprender (34) por considerar difícil (26) e, por conseguinte da reprovação (26) na área, e esse maior medo pode ser reflexo pelo tempo que ficaram sem estudar (40). Identificamos muitos pontos de destaques pelos alunos, o que eventualmente poderia ser trabalhado de modo simples, que provoque curiosidade e que pode contribuir na construção tanto na vida acadêmica quanto na vivência pessoal e profissional do aluno, no entanto tem se fechado os estudos de Matemática, apenas nos conteúdos escolares, presos em fórmulas, uma Matemática que não tem referência com as experiências vividas fora da escola.

Vale ressaltar a ideia de D’Ambrósio quando afirma que:

A matemática se impôs com forte presença em todas as áreas de conhecimento e em todas as ações do mundo moderno. Sua presença no futuro será certamente intensificada, mas não na forma praticada hoje. A aquisição dinâmica da matemática integrada nos saberes e fazeres do futuro depende de oferecer aos alunos experiências enriquecedoras. Cabe ao professor do futuro idealizar, organizar e facilitar essas experiências. (D’AMBRÓSIO, 2002, p.15).

A presença da Matemática é forte em qualquer área de conhecimento e também no nosso cotidiano. Vale no processo de ensino e de aprendizagem o enfoque na interdisciplinaridade e na veracidade do conhecimento prévio, uma vez que este tipo de conhecimento raramente é associado com os conteúdos escolares. Para garantir os estudos e o gosto pela Matemática é crucial fortalecer e possibilitar um estudo que aconteça estas relações, que o aluno perceba a importância e a correspondência da Matemática aprendida na escola com a Matemática utilizada em sua vida diária, que se torne interessante, curiosa e prazerosa e todo esse temor subtraia pelo gosto de estudá-la e aprendê-la.

É importante o professor ter a perspectiva de que compreender deve ser a principal finalidade do ensino, sustentado na convicção de que o aprendizado de Matemática, pelos alunos, é mais forte quando é autogerado do que quando lhes é imposto por um professor ou por um livro-texto (ONUCHIC, 1999).

No Eixo 2 foi analisado as Experiências Efetivas, segundo questionário online da Pesquisa de Avaliação, disponibilizado aos alunos para responder após finalizarem a área de Matemática. No primeiro Subeixo, analisamos como foram as experiências vivenciadas pelos alunos durante o processo de ensino e de aprendizagem na área de Matemática: aprendi muito (49); interativa (40); melhor experiência (36); produtiva (36); muito boa (34); descobri que tem como aprender Matemática (32); tirei muitas dúvidas (32); divertida (27); muito satisfeito (27); descobri o quanto a Matemática é importante/interessante (26); sinto-me mais seguro e 
confiante em Matemática (25); não é um bicho de sete cabeças (23); surpreendi-me com a Matemática (18); não houve dificuldade em aprender (17); tranquilo o ensino (17); gostei/amei (17); passei a gostar de Matemática (15), Passei a gostar, ainda, mais de Matemática (13); mais ou menos (06); tudo que estudei nada me servirá (01).

Neste subeixo os alunos foram questionados "como foram as suas experiências na área de Matemática", e dentre 24 alternativas, onde eles poderiam marcar mais de uma opção, quatro delas ficaram sem marcar: pior experiência (00); não aprendi nada nas Oficinas (00); passei a odiar a Matemática (00) e; não gostei, odiei (00).

Gráfico 4 - Experiência Efetiva: Como foram as suas experiências na Área de Matemática?

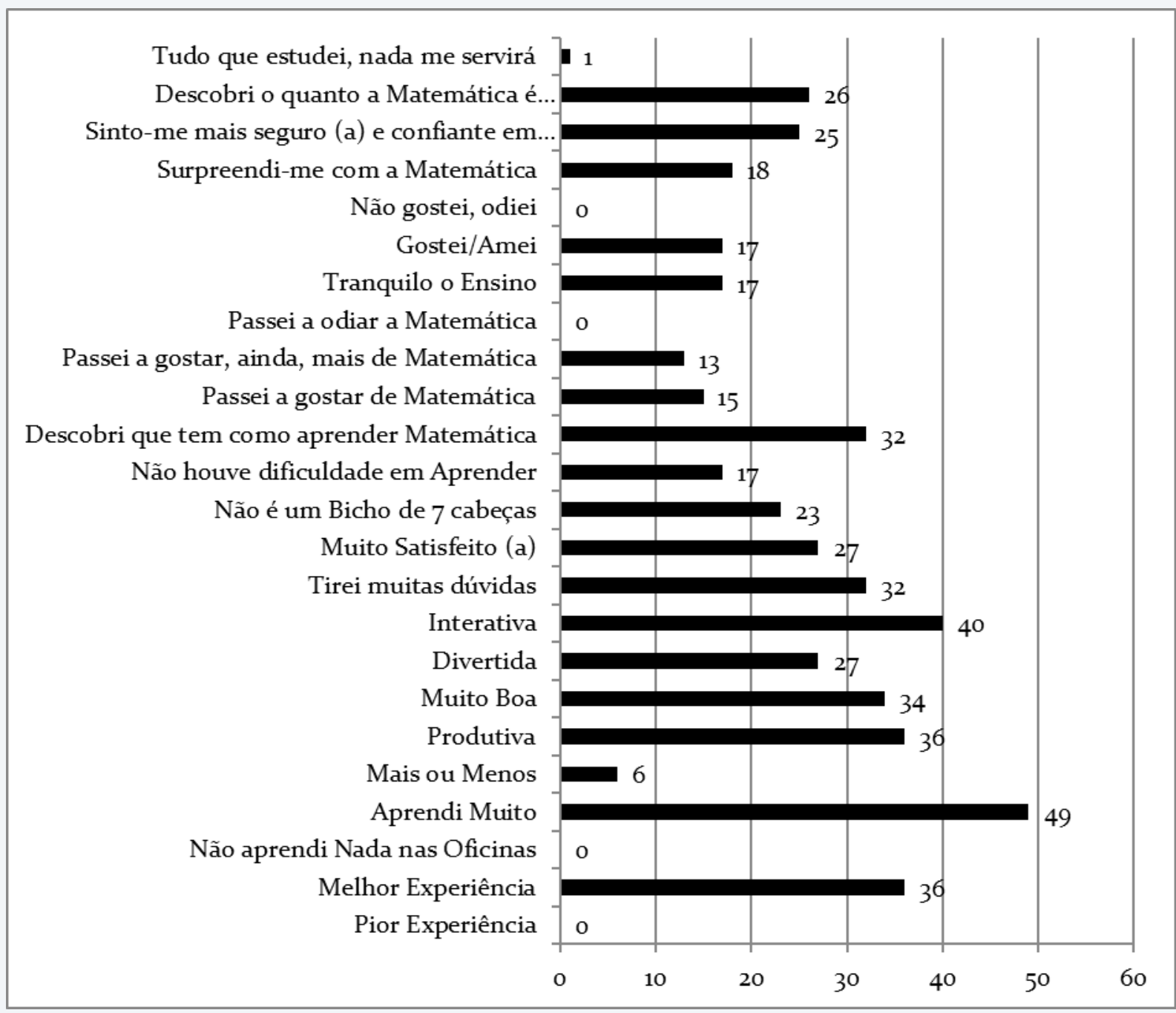

Os planejamentos desenvolvidos nas aulas/oficinas de Matemática foram pensados no contexto diário do aluno. Os jovens e adultos estudantes da escola Sesi, a grande maioria, são pessoas que trabalham nas fábricas ou no comércio da cidade. Desse modo, durante os quatro 
encontros, abordamos alguns conhecimentos matemáticos como: Porcentagem; Juros Simples e Compostos; Descontos; Estatística (Moda, Média, Mediana e Probabilidade); Raciocínio Lógico; Polinômios e; as Operações Fundamentais (Adição, Subtração, Multiplicação e Divisão).

Em todos os encontros os alunos utilizaram calculadoras, fizeram as suas anotações correspondentes as suas compreensões, pois em nenhum momento houve uso de lousa ou algum instrumento de projeção para escrever ou apresentar definições dos assuntos abordados, mas sim relações (Conhecimento prévio x Conteúdos escolares) e comunicações entre professor/aluno ou/e aluno/professor ou/e aluno/aluno, que favoreceram o entendimento do aluno.

A pesquisadora Onuchic (p. 205, 1999) ressalta que as aulas de matemática "deveriam tirar vantagem da força das calculadoras e computadores nos diferentes níveis de escolaridade". Visto que, essas flexibilidades possibilitaram muitos deles terem a melhor experiência (36), onde tiraram muitas dúvidas (32), perceberem que tem como aprender (32) e o quanto a Matemática é importante (26) na sua vida. O que estabeleceu, ainda, certa autoconfiança (25) e permitiu se surpreender (18), passar a gostar (15) e acreditar que a Matemática não é tão complicada (23).

As metodologias de ensino utilizadas asseguraram muita aprendizagem (49), de modo produtivo (36), interativo (40), divertido (27) e, ainda, de forma autônoma, onde eles construíam o seu próprio conhecimento, a partir das suas compreensões.

Como mencionado, anteriormente, difícil o objetivo de um planejamento atingir a todos, sendo assim é necessário está preparado para ser flexível em algumas situações. Nesses resultados, houve aquele aluno que reconheceu que todo o conhecimento debatido em sala de aula, nada o servirá (01) e outros afirmarem, também, que foi mais ou menos (06).

Possivelmente, estes números podem está relacionados com aqueles alunos mais inibidos, porventura se envergonharam em perguntar, tirar dúvidas e terminaram sem compreender algum assunto abordado nas oficinas. O que é normal encontrar em uma sala de aula, alunos que mesmo o professor possibilitando a sua participação, permitindo a sua autonomia, estabilidade, eles se mantêm inseguros, frágeis, incapazes de acreditar que aquilo o qual sabe ou pensa, esteja correto, o que pode provocar o não contentamento pela aprendizagem.

Em suma, considera-se que o objetivo em promover conhecimento e entusiasmo pela aprendizagem Matemática tenha acontecido, mesmo sabendo que nem toda a classe foi abrangida. Uma vez que, nenhum aluno considerou os encontros de Matemática como pior 
experiência ou passou a odiar a Matemática ou não ter gostado ou não ter aprendido nada em nenhuma Oficina. Prova que, mesmo aqueles alunos que afirmaram que a sua experiência foi "mais ou menos" ou que "nada o servirá", de algum modo aprendeu em determinado momento.

O segundo subeixo, buscamos verificar como ficaram os medos após todo o processo de ensino e de aprendizagem. Dentre cinco alternativas, quatro foram sinalizadas: sinto-me melhor (57), superei (28), não superei (01), não mudou nada (01), onde "me sinto pior" (00) não foi opção de nenhum aluno.

Gráfico 5 - Como ficaram os seus medos, após esse período de Ensino?

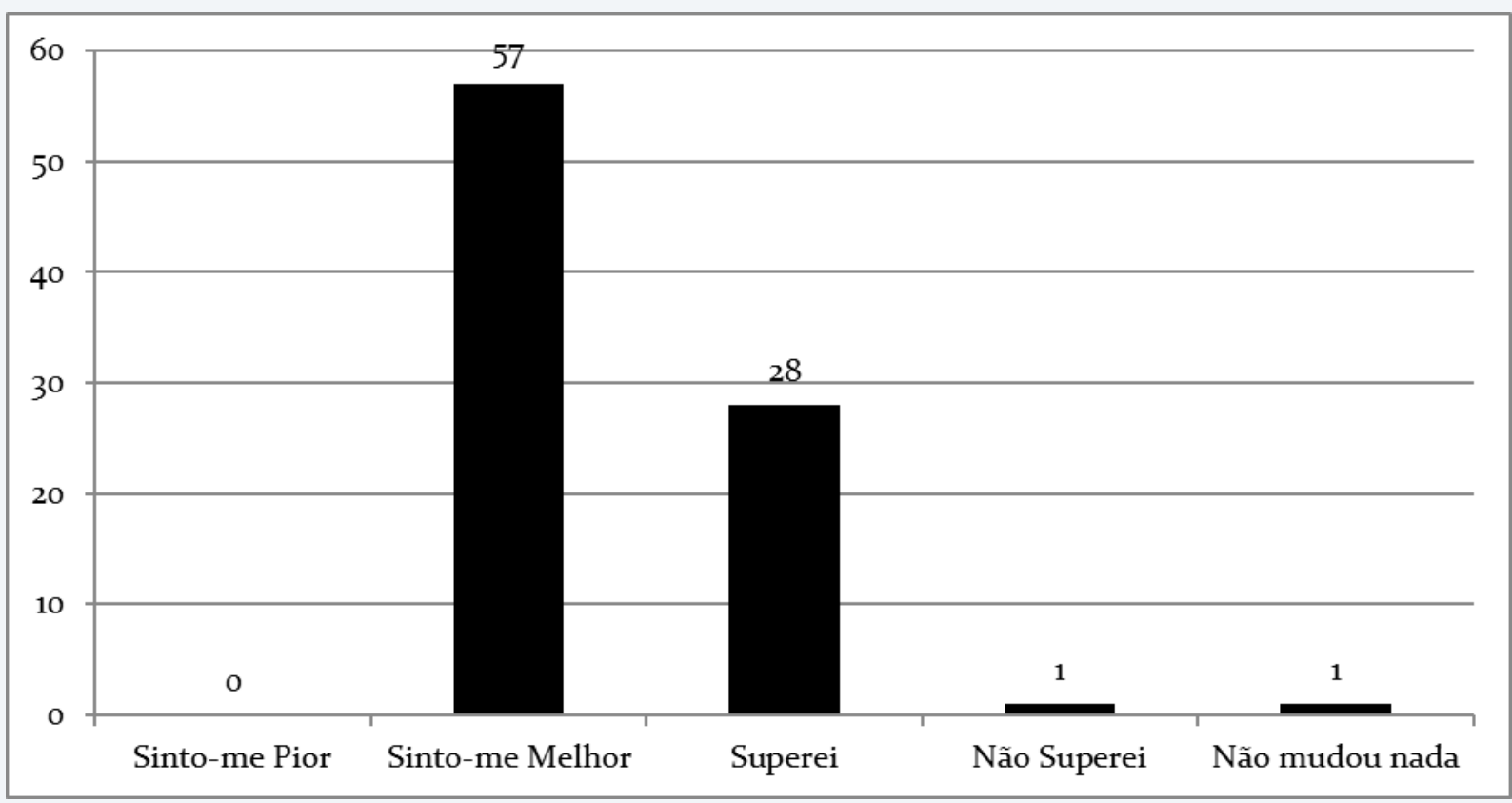

No Eixo 1 (Subeixo 2) foi analisado os medos dos alunos, no qual dos 87 participantes da pesquisa, 69 afirmaram ter medo da área de Matemática. E após todo o processo de ensino e de aprendizagem, ocorreram grandes mudanças onde, apenas dois alunos "não superou" (01) ou "não mudou nada" (01), referente ao seu temor com a Matemática.

Esses resultados fortalecem, ainda, mais a ideia de trabalhar com as diferentes metodologias do ensino de Matemática. Visto que, em meio as aversões, o cansaço, o tempo sem estudar, os alunos finalizaram melhores comparado, a partir do período de início de estudos da área. Berbel (2011) destaca que:

O engajamento do aluno em relação a novas aprendizagens, pela compreensão, pela escolha e pelo interesse, é condição essencial para 
ampliar suas possibilidades de exercitar a liberdade e a autonomia na tomada de decisões em diferentes momentos do processo que vivencia, preparandose para o exercício profissional futuro. Para isso, deverá contar com uma postura pedagógica de seus professores com características diferenciadas daquelas de controle. (BERBEL, 2011, p.29).

Entretanto, é necessário o professor fazer o diferente em sala de aula, a fim de atrair o aluno para novas descobertas, novos conhecimentos, que ele perceba a relação daquilo que está sendo estudado com a sua vida pessoal, profissional e constate a indispensabilidade de aprender. Crisostomo e Almeida (2017) constatou a potencialidade do modelo CDM na análise e sistematização da dimensão didática da Integral a partir dos relatos dos formadores pesquisados, desse modo, utilizar novos modelos na formação possibilita construção de conhecimentos sobre os processos de ensino.

O professor pode ser, eventualmente, autoridade em sala de aula, mas não é aquele que sabe mais. De fato, percebemos que os métodos tradicionais de ensino estabelecem a função do professor como o detentor do saber, ele que está no controle de tudo, nesse espaço o aluno é apenas um mero aprendiz, aquele que ouve, ver e escreve, sem a liberdade de fala.

Com estes modelos de ensino, dificilmente, existe a construção de conhecimento de forma autônoma, a superação dos medos ou o aluno se sentir bem, depois de um processo de ensino e de aprendizagem sustentado neste perfil. O comprometimento e o interesse do aluno pela aprendizagem podem ser despertados, mas quando as práticas pedagógicas desenvolvidas em sala de aula forem capazes de permitir a autonomia, a interatividade e o gosto pela aprendizagem, baseadas na realidade e vivência do aluno.

O último Subeixo avaliou a prática de ensino da tutora/professora da área de Matemática, o que está muito relacionado com as diferentes metodologias de ensino utilizadas em todas as práticas pedagógicas. Entre quinze possibilidades, nove foram assinaladas: ótimo (60); possui boa prática de ensino (48); nas suas aulas somos livres, temos autonomia (47); sabe ensinar (46); divertida (45); aprendi em todas as oficinas com ela (43); interativa (41); precisa melhorar a prática de ensino (02); não tem um bom relacionamento com os alunos/colegas (01).

Sobre as demais alternativas, correspondentes a este mesmo subeixo: péssimo (00); não sabe ensinar nada (00); não tem uma linguagem clara para ensinar (00); não aprendi nada com ela (00); não interage com os alunos (00); arrogante para ensinar. 
Gráfico 6 - O que diria sobre o ensino com a tutora/professora de Matemática?

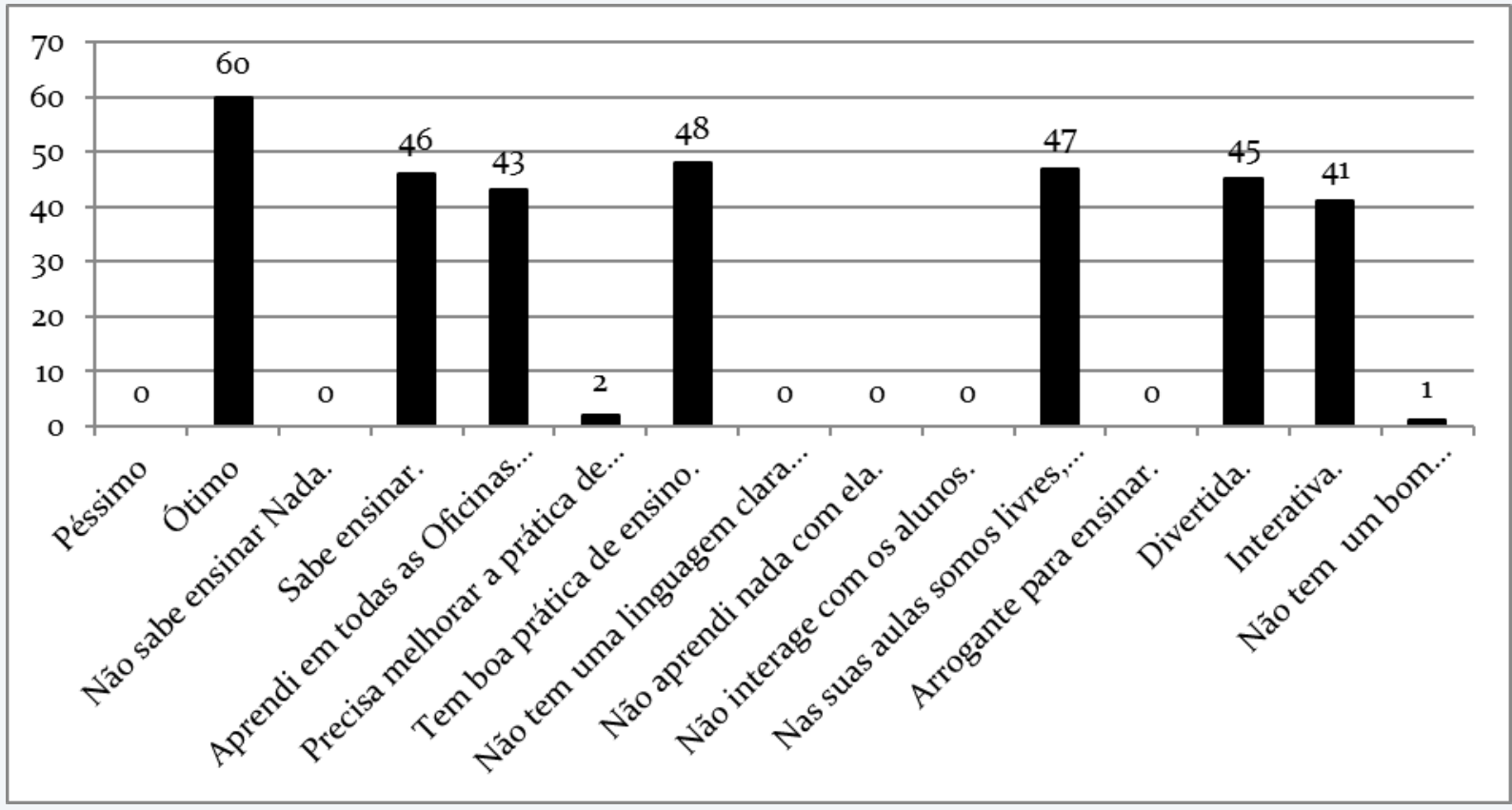

Uma coisa importante reconhecida nessa caminhada docente e que é reforçada, continuamente, com qualquer nova turma, primeiramente, ganhar a empatia de cada aluno, depois disso desenvolver as distintas metodologias de ensino. Uma vez que o aluno quando simpatiza com o professor, presumivelmente, ele se dedica mais, procura estar mais presente e participativo nas aulas, o que pode gerar maior interesse pela aprendizagem.

Sempre bom na prática de ensino o professor saber ouvir o seu aluno, atribuir importância, destaque, não relacionado a nota, mas reconhecimento em sala de aula pela sua participação, pela presença, pelo saber. Como já mencionado, anteriormente:

Quando muitos jovens e adultos retornam a escola, geralmente apresentam uma autoestima baixa, um sentimento de incapacidade de aprender e de desvalorização pessoal, marcados pelas experiências negativas vividas fora da escola (exclusão social) ou muitas vezes pelas experiências negativas vividas dentro da escola, como por exemplo, o fracasso escolar (exclusão educacional). Resgatar a autoestima desses jovens e adultos que vão para escola, bem como resgatar suas experiências e valorizar os seus saberes populares é um passo importante para garantir-lhes a aprendizagem e permanência na escola (NASCIMENTO, 2011, p.11).

Através dessas pequenas situações e reconhecimento que os alunos se sentem livres e autônomos (47) para construir o seu próprio conhecimento, que há aprendizado (43) e que constitui um bom relacionamento entre ambos (86), o que torna uma prática pedagógica interativa (41) e divertida (45). Como professor de matemática é fundamental está em sintonia 
com a grande missão do ser professor. Está minimamente equivocado o professor de matemática, que não percebe que há muito mais na sua função de professor, do que ensinar a fazer continhas ou a solucionar equações e problemas totalmente artificiais (D’AMBRÓSIO, 2002).

\section{Considerações Finais}

Que desafio é ensinar! Já dizia o amado Paulo Freire, ensinar é criar possibilidades para que o aluno seja capaz de construir o seu próprio conhecimento. Em outras palavras, é conceder ao aluno a oportunidade de pensar, de ser autônomo e interativo nas suas compreensões e na construção da sua aprendizagem.

As diversas metodologias do ensino de Matemática asseguram estes méritos, vale a pena o professor buscar, estudar, analisar e desenvolver aquelas que correspondem o perfil da sua turma e desenvolvê-las. Vale ressaltar que não é simples trabalhar com aquilo que não temos tanta prática, mas quando percebemos a euforia do aluno pela aprendizagem é uma satisfação gigante, onde somos capazes de buscar mais e mais coisas novas para produzir em sala de aula.

Bom que existem os diferentes tipos de pesquisas que possibilitam uma análise sobre a nossa prática de ensino e, ainda, existem nesses resultados aqueles pontos considerados negativos, para não nos acomodarmos, mas refletir e buscar cada vez mais melhorias para o processo de ensino e de aprendizagem.

Com os resultados apresentados, ficou evidente o quanto as metodologias de ensino utilizadas foram eficientes e capazes de promover aprendizagem aos alunos, de forma interativa, autônoma, crítica e prazerosa. Reflexo disso são as superações dos medos com a temida Matemática, onde 97,7\% (85) dos alunos participantes finalizaram os estudos da área melhor, comparados ao momento antes do início da área.

Vale destacar que todos os conhecimentos matemáticos abordados em sala de aula estavam muito próximos da realidade pessoal e profissional do aluno, o que despertou curiosidade, motivação e satisfação pelas abordagens matemáticas, na qual geraram diversas compreensões, ideias, relações, aprendizagens e, também, dúvidas. Enfim, foram momentos de muita extroversão, talvez, de estranheza no início, entretanto serenidade com os objetivos propostos - alcançar a construção de conhecimento. 


\section{REFERÊNCIAS}

ALMEIDA, Lourdes Maria Werle de; DIAS, Michele Regiane. Um estudo sobre o uso da Modelagem Matemática como estratégia de ensino e aprendizagem. Bolema, ano 12, $\mathrm{n}^{\mathrm{o}} 22$, pp.19-36. 2004. Disponível em: <

http://www.furb.br/cremm/arquivos.php?secao=2\&texto=1>. Acesso em: 18 dez. 2018.

ANDRADE, Silvânio. Ensino-aprendizagem de matemática via resolução, exploração, codificação e descodificação de problemas. Rio Claro, 1998. Dissertação (Mestrado em Educação Matemática). Universidade Estadual Paulista, Rio Claro, 1998.

BARDIN, Laurence. Análise de conteúdo. 4 ed. Lisboa, Portugal: Edições 70, LDA, 2010.

BASSANEZI, Rodney Carlos. Ensino-aprendizagem com modelagem matemática: uma nova estratégia. São Paulo: Editora Contexto. 2002.

BERBEL, Neusi Aparecida Navas. As metodologias ativas e a promoção da autonomia de estudantes. Semina: Ciências Sociais e Humanas, Londrina, v. 32, n. 1, p. 25-40, jan./jun. 2011. Disponível em: <

http://www.uel.br/revistas/uel/index.php/seminasoc/article/view/10326/0. Acesso em: 15 dez. 2018.

CRISOSTOMO, Edson; ALMEIDA, Shirley Patrícia Nogueira de Castro. Conocimientos didáctico-matemáticos de profesores en la perspectiva de la educación matemática. Práxis Educacional, [S.1.], v. 13, n. 25, p. 291-312, abr. 2017. Disponível em:

http://periodicos2.uesb.br/index.php/praxis/article/view/965. Acesso em: 18 dez.2018.

D’AMBROSIO, Ubiratan. Etnomatemática e Educação. Reflexão e Ação, v. 10, n. 1, p. 7-19, 2002. Disponível em: <

http://www.joinville.udesc.br/portal/professores/regina/materiais/etnomatem_tica_revista.pdf \#page=5. Acesso em: $18 \mathrm{dez} .2018$.

D’AMBROSIO, Ubiratan. Etnomatemática: elo entre as tradições e a modernidade. 2.ed. Belo Horizonte: Autêntica, 2002.

D'AVILA, Cristina; FERREIRA, Lúcia Gracia. Concepções Pedagógicas na Educação Superior: abordagens de ontem e de hoje. In: D'AVILA, Cristina; MADEIRA, Ana Verena (orgs.). Ateliê didático: uma abordagem criativa na formação continuada de docentes universitários. Salvador: EDUFBA, 2018. p. 21-46.

GIL, Antônio Carlos. Métodos e técnicas de pesquisa social. São Paulo, Atlas, 1987.

MORETTO, Vasco Pedro. Planejamento: planejando a educação para o desenvolvimento de competências. 10. ed. Petrópolis: Vozes, 2014.

NASCIMENTO, Juliane do. A Educação de Jovens e Adultos no Brasil: a problemática da alfabetização no país. In: X CONGRESSO NACIONAL DE EDUCAÇÃO, 2011. Curitiba. Anais do EDUCERE. Pontifica Universidade Católica do Paraná, 2011. Disponível em: < http://educere.bruc.com.br/CD2011/pdf/4660_3396.pdf. Acesso em: 14 out. 2018. 
ONUCHIC. Lurdes, De La Rosa. Ensino-Aprendizagem de Matemática através da Resolução de Problemas. In: BICUDO, M. A. V. (Orgs.) Pesquisa em Educação Matemática:

Concepções e Perspectivas. São Paulo: Editora UNESP, 1999. p. 199-218.

SADOVSKY, Patrícia. Falta fundamentação didática no ensino de matemática. Revista Nova escola, Editora Abril, São Paulo. Ed. Especial 14. p. 08-10. Jul. 2007.

UNIVERSIDADE FEDERAL DO RECÔNCAVO DA BAHIA. Moodle para professores e tutores em EAD (Curso sem tutoria). Cruz das Almas-BA, 2015.

\section{SOBRE A AUTORA:}

\section{Adriana Guerra}

Professora do Instituto Federal de Educação, Ciência e Tecnologia Baiano (IFBaiano), Campus Guanambi, e do Serviço Social da Indústria (SESI). Grupo de Pesquisa e Estudos Pedagógicos (GPEP). E-mail: drylguerra@ hotmail.com

http://orcid.org/0000-0002-9731-8933

Recebido em: 18 de fevereiro de 2018

Aprovado em: 23 de abril de 2019

Publicado em: 01 de outubro de 2019 